www.jmscr.igmpublication.org

Impact Factor (SJIF): 6.379

Index Copernicus Value: 71.58

ISSN (e)-2347-176x ISSN (p) 2455-0450

crossref DOI: _https://dx.doi.org/10.18535/jmscr/v6i5.49

Journal Of Medical Science And Clinical Research

\title{
To Study the Skin in Thyroid Dysfunction at Rajindra Hospital, Patiala
}

Authors

\author{
Dr Abhishek Malviya ${ }^{1}$ (Asst. Prof.) \& Dr Santpal Sangwan ${ }^{2}$ (Clinician) \\ ${ }^{1}$ Dept. of DVL (Skin \& V.D.), Amaltas Institute of Medical Science, Dewas \\ ${ }^{2}$ Private Medical Practice \\ Corresponding Author \\ Dr Santpal Sangwan
}

\begin{abstract}
The present study was undertaken to study various Dermatological manifestations in Thyroid disorders in patients attending outpatients Of Skin and V.D. and Medicine Departments and also Inpatients of both Departments. Also various dermatological conditions were observed which can be associated with Thyroid disorders.

The results were compiled, tabulated and compared with those reported in previous studies.

Following conclusions were drawn from the study.

- Thyroid disorders are quiet common in Northern India.

- Females are more commonly affected then Males.

- In our study $92 \%$ patients were Females.

Skin manifestations were present in $92 \%$ of patients.

- Pruritus was also a common presenting complaint in many patients (20\%)

- Most common Dermatological manifestation in this group of patients was generalized xerosis (54\%)

Keywords: Thyroid, Dysfunction \& Skin.
\end{abstract}

\section{Introduction}

Causes of hyperthyroidism and hypothyroidism can be divided as primary and secondary. Primary cause is related to the thyroid gland itself while the secondary causes are related to defect in pituitary gland and hypothalamus. ${ }^{1}$

Iodine deficiency is the most common cause of hypothyroidism worldwide. ${ }^{1}$ The northern frontiers from India extending from Kashmir in the west to Assam in the east, form an extensive Himalayan goitre belt. Environmental deficiency of iodine is the primary factor responsible for endemic goitre in these areas. ${ }^{2}$ For thyrotoxicosis, Grave's disease is the most common cause. ${ }^{1}$
Dermatological Manifestations of Thyroid Disorders

These are categorized as: ${ }^{3}$

1. Direct action of thyroid hormone on skin tissues.

2. Skin manifestations of direct thyroid hormone action on non skin tissues.

3. Autoimmune skin diseases associated with thyroid dysfunction of autoimmune etiology.

Study Design: Retrospective Study 


\section{Material \& Method}

The study would be conducted in diagnosed patients of Thyroid disorders attending the outpatient Department and Hospitalized patients in Rajindra Hospital, Patiala over a period of one year. The diagnosis of thyroid disease would be made by the physician depending upon the clinical, biochemical, radionuclear studies and histopathological findings as per the requirement.

\section{Methods}

\section{Inclusion Criteria}

1. Diagnosed thyroid disease patients who are not on treatment.

2. Thyroid disease patients on treatment but with deranged thyroid function tests at the time of examination.

\section{Exclusion Criteria}

1. Pregnancy.

2. Pediatric age group less than 16 years.

Techniques used for the Quantitative Measurement of Thyroid Function Tests

\begin{tabular}{|l|c|}
\hline TEST & TECHNIQUE \\
\hline Free T3 & FT3 ELISA Kit \\
\hline Free T4 & FT4 ELISA Kit \\
\hline TSH & Streptavidin Biotin Technology \\
\hline
\end{tabular}

Thyroid Scan: Tc pertechnetate is used for thyroid imaging and studying the radioactive tracer fractional uptake.

Informed consent for inclusion into study, photography and relevant investigations will be taken as per the consent form.

\section{Observation \& Results}

\section{Hyperthyroidism: General Observations}

Table 1: Age- Most Commonly Hyperthyroidism is seen in 3rd decade in our study (42\%) i.e 21 out of 50 patients, followed by in 4th decade (34\%) i.e 17 out of 50 patients and 5 th decade $(20 \%)$ i.e 10 out of 50 patients with Mean age Range: $33.30 \pm 8.63$

\begin{tabular}{|l|c|c|}
\hline Age & No of Patient & Percentage \\
\hline $11-20$ & 2 & $4 \%$ \\
\hline $21-30$ & 21 & $42 \%$ \\
\hline $31-40$ & 17 & $34 \%$ \\
\hline $41-50$ & 10 & $20 \%$ \\
\hline Total & 50 & $100 \%$ \\
\hline
\end{tabular}

Fig 1: Mean Range: $33.30 \pm 8.63$

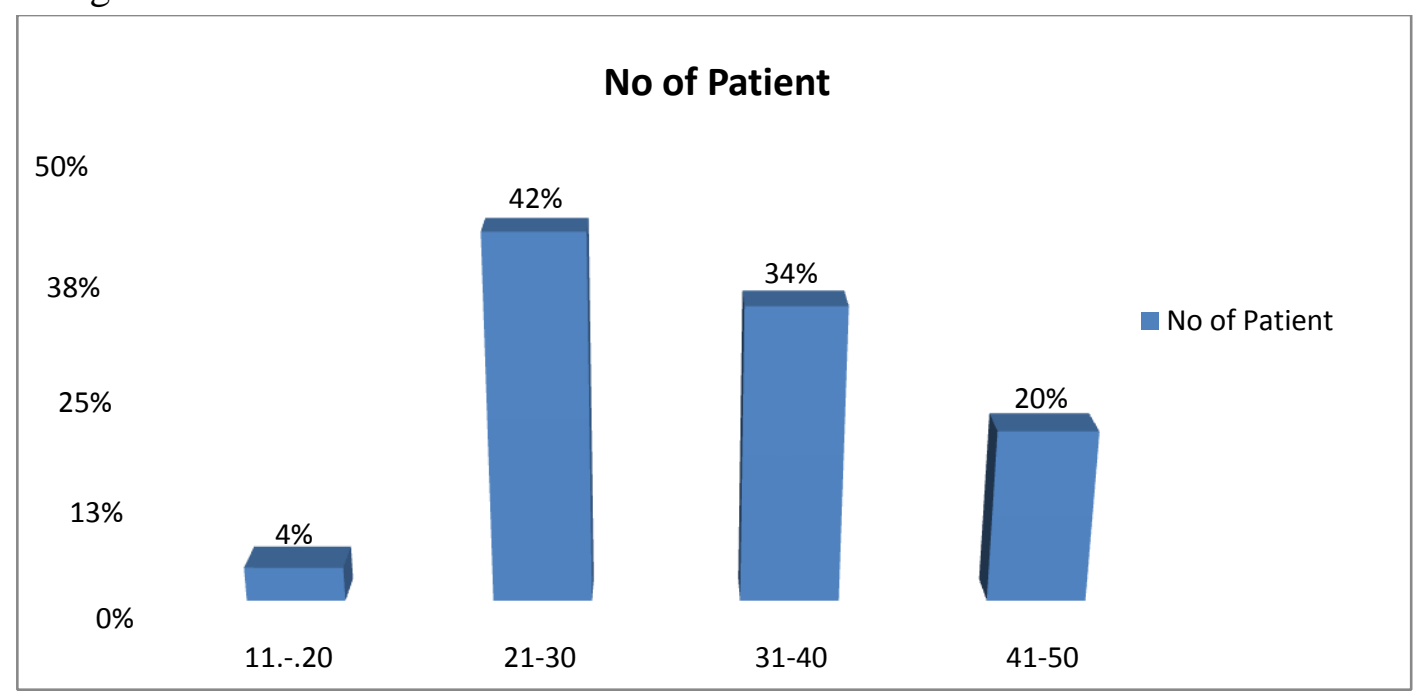

Sex: Hyperthyroidism was more common in females ( $94 \%$ of female patients) i.e 47 out of 50 patients as compared to males $(6 \%)$ i.e 3 out of 50 patients. 
Table 2: Gender

\begin{tabular}{|c|c|c|}
\hline Gender & Frequency & Percentage \\
\hline Female & 47 & $94 \%$ \\
\hline Male & 3 & $6 \%$ \\
\hline Total & 50 & $100 \%$ \\
\hline
\end{tabular}

Table 3: Age * Gender

\begin{tabular}{|l|c|c|c|c|c|c|}
\hline \multirow{2}{*}{ Age } & \multicolumn{4}{|c|}{ Gender } & \multicolumn{2}{c|}{} \\
\cline { 2 - 7 } & Frequency & Percentage & Frequency & Percentage & Frequency & Percentage \\
\hline $11-20$ & 2 & $4 \%$ & 0 & $0 \%$ & 2 & $4 \%$ \\
\hline $21-30$ & 19 & $38 \%$ & 2 & $4 \%$ & 21 & $42 \%$ \\
\hline $31-40$ & 16 & $32 \%$ & 1 & $2 \%$ & 17 & $34 \%$ \\
\hline $41-50$ & 10 & $20 \%$ & 0 & $0 \%$ & 10 & $20 \%$ \\
\hline Total & 47 & $94 \%$ & 3 & $6 \%$ & 50 & $100 \%$ \\
\hline
\end{tabular}

\section{Discussion}

The long-recognized "thyroid-skin connection "encompasses many layers of complexity; the more one explores this connection, the more biologically fascinating and clinically important questions arise., ${ }^{4,5}$

Both abnormally low and excessively high serum levels of thyroid hormones (THs) can alter the appearance and function of human skin and its appendages, leading to various clinical manifestations. Much less obvious, however, are the underlying mechanisms that cause these changes. $^{4,6}$

For example, human skin and its appendages are known to express $\mathrm{TH}$ receptors (TR $\beta 1$ ), and THs are known to alter the expression of selected keratins. $^{7,8}$

van Beek et al. (2008) recently demonstrated that THs can prolong the duration of hair growth (anagen phase) and that they can stimulate hair matrix keratinocyte proliferation, hair pigmentation, and even the gene and protein expression for selected keratins in serum-free organ culture (i.e., under "hypothyroid" growth conditions). In addition, THs stimulate hair growth and promote wound healing in mice. ${ }^{9}$

\section{Hypothyroidism}

Age

In our study it has been observed that Hypothyroidism was more common in the 4th decade of life $(50 \%)$. This is followed by the 5 th decade $(20 \%)$ then in 3 rd decade $(16 \%)$ of life. Mean Range: $37.60 \pm 10.67$

Gender: Hypothyroidism was found more commonly in Females (90\%).

Male to Female ratio in our study was 1:9.

In a study done by Alka et al in 2006, Male:Female was found to be 1:7 which is comparable to our study. ${ }^{10}$

\section{Hyperthyroidism}

Age: Most Commonly Hyperthyroidism is seen in 3rd decade in our study(42\%) followed by in 4 th decade $(34 \%)$ and 5 th decade(20\%).

Sex: Hyperthyroidism was more common in females (94\% of female patients) as compared to males $(6 \%)$

Mean Range: $33.30 \pm 8.63$ years. 


\section{Conclusion}

Concluding both groups separately

\section{Hypothyroid Patients}

- Age/Sex-Thyroid Disorders are more common in Females.

- Female: Male came out to be 9:1.

- Age group most commonly affected was Young adults and adults (4th - 6th decades of life).

- Mean range for age was $37.60+-10.67 \mathrm{yrs}$.

- Most common general complaints with which patients came was Weight gain (70\%) followed by lethargy and Weakness $(62 \%)$

\section{Associated}

Dermatological

Diseases

\section{(Hypothyroid Group)}

- Vitiligo was seen in $6 \%$ patients.

- Chronic Urticaria was seen in $20 \%$ patients.

- Pigmentation was seen in $42 \%$ of patients.

- Acanthosis Nigricans was seen in $10 \%$ of patients.

- Melasma was seen in $14 \%$ patients.

- Lichen Planus Pigmentosus was seen in $10 \%$ patients.

- Alopecia Areata was seen in $2 \%$ patients.

- Syringoma was seen in $2 \%$ patients.

- Skin Tag is seen in $2 \%$ patients.

\section{Hyperthyroid Group}

- Most common presenting complaint in this group was Weight loss Palpitation and increased appetite seen in $68 \%$ of patients.

- Females were more commonly affected then males ( $94 \%$ females)

- Pruritus was presenting complaint in $12 \%$ of patients.

- Most common dermatological sign/ symptom observed was warm skin (54\%) followed by generalised hyperhidrosis $(48 \%)$ then smooth velvety skin $(40 \%)$.

- Exophthalmos 38\% and Lid Lag 44\% were also quiet common.

- Facial Flushing 20\%, palmar erythema $6 \%$, Jellinek's Sign 6\% and non specific pigmentation

$6 \%$

were

other signs/symptoms observed.

- Hyperpigmentation which was very frequent in Hypothyroid group was seen in only $8 \%$ of Hyperthyroid Patients.

- Out of all 50 Hyperthyroid patients observed, $58 \%$ had complaints related to

\section{Associated Dermatological Diseases (Hyperthyroid Group)}

- Acanthosis Nigricans was seen in $4 \%$ of patients.

- Alopecia Areata was seen in $4 \%$ of patients.

- Chronic Urticaria was seen in $6 \%$ of patients.

- Melasma was seen in $6 \%$ of patients.

- Vitiligo was seen in $4 \%$ of patients.

\section{References}

1. J. Larry Jameson, Anthony P. Weetman. Disorders of the Thyroid Gland. In: Dan L. Longo, Anthony S. Fauci, Dennis L. Kasper et al. Harrison's Principles of Internal Medicine. $18^{\text {th }}$ ed. United States of America: The McGraw Hill Companies; 2012.

2. M.G. Karmarkar, M.G. Deo, N. Kochupillai et al. Pathophysiology of Himalayan endemic goiter. The American Journal of Clinical nutrition 1974; 27: 96-103.

3. Joshua D.Safer. Thyroid Hormone Action on Skin. Dermatoendocrinol 2011; 3 (3): 211-215.

4. Freinkel RK, Freinkel N. (1972) Hair growth and alopecia in hypothyroidism. Arch Dermatol 106:349-52 .

5. Slominski A, Wortsman J, Kohn L et al. (2002) Expression of hypothalamicpituitary-thyroid axis related genes in the human skin. J Invest Dermatol 119:144955.

6. Billoni N, Buan B, Gautier B et al. (2000) Thyroid hormone receptor betal is expressed in the human hair follicle. $\mathrm{Br} \mathrm{J}$ Dermatol 142:645-52. 
7. Ramot Y, Paus R, Tiede S et al. (2009) Endocrine controls of keratin expression. Bioessays 31:389-99

8. Van Beek N, Bod E, Kromminga A et al. (2008) Thyroid hormones directly alter human hair follicle functions: anagen prolongation and stimulation of both hair matrix keratinocyte proliferation and hair pigmentation. J Clin Endocrinol Metab 93:4381-8

9. Safer JD, Crawford TM, Holick MF. (2005) Topical thyroid hormone accelerates wound healing in mice. Endocrinology 146:442530

10. Alka Dogra, Aman Dua, Parminder Singh. Thyroid and Skin. Indian J Dermatol 2006; 51 (2): 96-99. 